\title{
FGFR2 NM_000141.4:C.1647T>A
}

National Cancer Institute

\section{Source}

National Cancer Institute. FGFR2 NM 000141.4:C.1647T>A. NCI Thesaurus. Code C107598.

A nucleotide substitution at position 1647 of the coding sequence of the FGFR2 gene where thymine has been mutated to adenine. 